\title{
Macrophage-like THP-1 cells show effective uptake of silica nanoparticles carrying inactivated diphtheria toxoid for vaccination
}

\author{
Xinyue Huang • Danielle Paixão Cavalcante • \\ Helen E Townley
}

Received: 18 July 2019 / Accepted: 22 November 2019 / Published online: 8 January 2020

(C) The Author(s) 2020

\begin{abstract}
Nanoparticles may be used in vaccinology as an antigen delivery and/or an immunostimulant to enhance immunity. Porous silica has been identified as an effective adjuvant for more than a decade, and we have therefore investigated the take up rate by an immortalized macrophage-like cell line of a number of mesoporous silica nanoparticles (MSNPs) with differing diameter and pore size. The MSNPs were synthesized using a sol-gel reaction and post-synthesis removal of the template. The MSNPs showed a clear distribution in take up rate peaking at $217 \mathrm{~nm}$, whereas a comparison with solid spherical nanoparticles showed a similar distribution peaking at $377 \mathrm{~nm}$. The MSNPs were investigated before and after loading with antigen. Diphtheria toxoid was used as a proof-of-concept antigen and showed a peak macrophage internalization of $53.42 \%$ for loaded LP3 particles which had a diameter of $217.75 \pm 5.44 \mathrm{~nm}$ and large $16.5 \mathrm{~nm}$ pores. Optimal MSNP sizes appeared to be in the $200-400 \mathrm{~nm}$ range, and larger pores showed better antigen loading. The mesoporous silica particles
\end{abstract}

\section{Huang $\cdot$ H. E. Townley}

Nuffield Department of women's and reproductive health, Oxford University, John Radcliffe Hospital, Oxford, UK

D. P. Cavalcante

Cristália Produtos Químicos Farmacêuticos Ltda, Sao Paulo, Brazil

H. E. Townley $(\bowtie)$

Department of Engineering Science, Oxford University, Park's

Road, Oxford, UK

e-mail: Helen.Townley@eng.ox.ac.uk were shown to be generally biocompatible, and cell viability was not altered by the loading of particles with or without antigen.

Keywords Nanoparticle $\cdot$ Vaccine $\cdot$ Antigen $\cdot$ Silica . Macrophage $\cdot$ Nanomedicine

\section{Introduction}

Nanovaccinology involves the use of nanometre sized particles as a means to deliver antigen, in order to enhance antigen processing. A variety of engineered nanoparticles have been developed for vaccine development and while they differ in size, shape and composition, they are typically $25-200 \mathrm{~nm}$ in diameter (Zhao et al. 2014). The large surface area to volume ratio of nanoparticles means that the particles may carry a higher proportion of antigen for immune activation. The size of the nanoparticle systems also increases the likelihood that they will accumulate in lymph nodes. This can both increase their effective concentration and reduce systemic reactivity (Nuhn et al. 2016). Our previous work compared the antigen loading and unloading capacity of mesoporous silica nanoparticles (MSNPs), with a variety of different pore sizes, and external diameters (Huang et al. submitted). Herein, we investigate the ability of the different particles to be internalized by antigen-presenting cells. The uptake of nanoparticles, and subsequent immune response, may be due to their intrinsic resemblance to natural viruses (Chattopadhyay 
et al. 2017). Since the immune system is primed to recognize viruses, it is not surprising that nanoparticles which can be similar in terms of size, geometry and antigen display could be effective. Soluble antigens are well known to have low efficacy in inducing good protective immunity. This is largely due to the insufficient uptake of the antigen by antigen-presenting cells (APCs). Attaching soluble vaccine antigens to larger carriers can facilitate recognition and uptake by the APCs (Pobre et al. 2014).

Materials used for the production of nanoparticles for antigen delivery include lipids, polymers and inorganic compounds. For our study, we have chosen to investigate the use of silica nanoparticles as a carrier for antigen molecules due to a number of favourable properties: Silica nanoparticles can be synthesized in a range of sizes and shapes and can be controlled using sol-gel chemistry and is a particularly useful material to work with since nanoscale pores can be easily integrated to generate MSNPs which have a very large surface area for carrying antigen. In addition to the size of the particles, charge is also an important parameter. Some studies have shown that cationic nanoparticles show higher uptake due to the interaction with anionic cell membranes (Foged et al. 2005). However, cationic particles are more likely to induce haemolysis and platelet aggregation than neutral or anionic particles (McCusker et al. 2004). The negatively charged silanol groups found on the surface of silica are also beneficial if further modification with additional functional molecules such as those for cell recognition is needed.

The attachment of a vaccine antigen to a nanoparticle may be via chemical conjugation or physical adsorption. In this study, we have used physical adsorption which is simply based on the charge or hydrophobic interaction of the antigen and the nanoparticle material. Conjugation could potentially result in modification of the antigen as a result of the binding to the nanoparticle surface, potentially leading to a less immunogenic antigen.

In addition, silica has been shown to be biocompatible, and the pore size can be carefully controlled to determine the optimal size to adsorb and deliver antigen. While the silica itself can be used as an adjuvant and is capable of inducing strong humoral and cellular immune responses against the relevant antigens, others can also be added as cargo (Mahony et al. 2013). To date, silica has been investigated in formulations for vaccine applications against $E$. coli, porcine circovirus and HIV (Guo et al. 2012; Mercuri et al. 2006; Cheng et al. 2012). Furthermore, in contrast to other nanoparticles such as gold, silica is also easily degraded (Huang et al. 2014) in the body and can then be excreted in the urine.

Irrespective of the material chosen, to be effective as a vaccine delivery system, it is essential that the microor nanoparticles are internalized by antigen-presenting cells (Alshanqiti et al. 2017). We have therefore investigated the uptake of our library of silica nanoparticles using the human cell line THP-1 as a model system. THP-1 is an immortalized monocyte-like cell line, derived from the peripheral blood of a childhood case of monocytic leukaemia (M5 subtype) (Tsuchiya et al. 1980). These cells can be differentiated into macrophage-like cells using phorbol-12-myristate-13acetate (PMA) which activates protein kinase $\mathrm{C}$ (PKC). The resulting cells resemble mature macrophages, with increased adherence and loss of proliferative activity (Schwende et al. 1996). The cells can be confirmed to be macrophage-like by the expression of CD-14, a 53-55 kDa glycosylphosphatidylinositol (GPI)-linked membrane glycoprotein.

As a proof-of-concept, we have loaded the nanoparticles with the inactivated diphtheria toxoid (DT). DT is secreted as a single polypeptide of $58 \mathrm{kDa}$ by pathogenic strains of Corynebacterium diphtheria. Subsequently, the 535 amino acid polypeptide is proteolyzed to two polypeptide chains linked by a disulphide bond. The DT is well characterized and has been used since the 1920s when the first methods to inactivate the toxoids were introduced (Ramon 1924; Glenny and Hopkins 1923). This study therefore investigates the uptake rates of macrophages of loaded and unloaded MSNPs, with different external diameters and pore sizes.

\section{Materials and methods}

THP-1 cell culture

THP-1 cells were donated by Dr. Paul Klenerman (Nuffield Department of Medicine, University of Oxford). Cells were maintained in RPMI 1640 media supplemented (Life Technologies) with 10\% fetal calf serum (FCS; Sigma-Aldrich), 2 mM L-glutamine (SigmaAldrich), $100 \mathrm{U} / \mathrm{mL}$ penicillin (Sigma-Aldrich), $0.1 \mathrm{mg} /$ $\mathrm{mL}$ streptomycin (Sigma-Aldrich) and $0.05 \mathrm{mM} \mathrm{2-}$ mercaptoethanol (Sigma-Aldrich). Cells were incubated 
at $37{ }^{\circ} \mathrm{C}$ in a $5 \% \mathrm{CO}_{2}$ atmosphere. Cells were passaged every 4-5 days and discarded after 30 passages.

THP-1 cell differentiation

THP-1 cells (from 5th generation to 30th) were resuspended in RPMI media at a concentration of $2 \times$ $10^{5}$ cells $/ \mathrm{mL}$ and treated with $100 \mathrm{ng} / \mathrm{mL}$ phorbol 12 myristate 13-acetate (PMA; Sigma). Cells were then plated in a $24-w e l l$ plate $(1 \mathrm{~mL}$ per well) and incubated for $72 \mathrm{~h}$ at $37^{\circ} \mathrm{C}, 5 \% \mathrm{CO}_{2}$. The PMA-containing media was then removed and replaced with fresh RPMI media for $24 \mathrm{~h}$ before further experiment.

\section{Evaluation of differentiation}

The CD-14 marker on PMA-differentiated and undifferentiated cells were compared by flow cytometry since CD-14 is considered a surface marker of macrophages. THP-1 cells were collected and washed with PBS. The Fc receptor was blocked by resuspending cells at $1 \times$ $10^{4}$ cells $/ \mathrm{mL}$ in $5 \mu \mathrm{g} / \mathrm{mL} \mathrm{IgG} \mathrm{(Sigma)} \mathrm{in} \mathrm{PBS} \mathrm{at} \mathrm{a} \mathrm{total}$ volume of $100 \mu \mathrm{L}$ and incubating on ice for $20 \mathrm{~min}$. Subsequently, $5 \mu \mathrm{L}$ of APC-CD-14 primary antibody (BioLegend) was added and incubated on ice for a further $20 \mathrm{~min}$. Cells were collected by centrifugation and the supernatant removed. Cells were washed in $200 \mu \mathrm{L}$ PBS and then centrifuged and resuspended in $200 \mu \mathrm{L}$ PBS.

Controls were also prepared, including undifferentiated THP- 1 cells incubated with only IgG and undifferentiated cells incubated with both IgG and anti-CD14 antibodies.

\section{Phagocytosis assay}

The differentiated THP- 1 cells $\left(2 \times 10^{5}\right.$ cell/well $)$ were treated with $10 \mu \mathrm{g} / \mathrm{mL}$ fluorescein isothiocyanate (FITC)-labelled MSNPs for $2 \mathrm{~h}$ at $37{ }^{\circ} \mathrm{C}$. After the treatment, the cells were resuspended and fixed in $100 \mu \mathrm{L}$ cold $2 \%$ paraformaldehyde for $10 \mathrm{~min}$ on ice. The phagocytosis efficacy was evaluated using FACS.

The negative control was performed on low temperature $\left(4^{\circ} \mathrm{C}\right)$ while the other parameters of MSNP treatment remain the same. The net phagocytosis efficacy was evaluated by subtracting the result of the negative control for the experiment.
Fluorescence activated cell sorting

Fluorescence activated cell sorting (FACS) was run on a FACSCalibur TM. All data was collected using CellQuest $^{\mathrm{TM}}$ Pro (BD Biosciences). The data was analysed using Kaluza ${ }^{\mathrm{TM}}$ 1.2.

Viability assay

Cells were incubated with nanoparticles for $2 \mathrm{~h}$. The particle suspension was then removed and replaced with $100 \mu \mathrm{l}$ of $0.5 \mathrm{mg} / \mathrm{mL}$ MTT (3-(4,5-dimethylthiazol-2yl)-2,5-diphenyltetrazolium bromide; Life Technologies) solution in culture medium. The plate was wrapped in foil and the cells were incubated for a further $2 \mathrm{~h}$, at $37^{\circ} \mathrm{C}$. An aliquot of the media $(75 \mu \mathrm{l})$ was removed and $150 \mu \mathrm{l}$ of dimethyl sulfoxide (DMSO; Sigma) was added to the plate. The absorbance was read at $590 \mathrm{~nm}$ after solubilization of the precipitate.

Synthesis protocol for solid silica nanoparticles

Synthesis of SNP01, 02, 03

Absolute ethanol (48 mL; Fisher Scientific) was mixed with $3 \mathrm{~mL}$ deionized water and $3 \mathrm{~mL}$ ammonium hydroxide (28-30\%; Sigma) in a flask and placed on a heated stirrer. The temperature was either set to (i) $75^{\circ} \mathrm{C}$ for SNP01, (ii) $48{ }^{\circ} \mathrm{C}$ for SNP02 or (iii) $52{ }^{\circ} \mathrm{C}$ for SNP03. Once the temperature was stable, $3 \mathrm{~mL}$ tetraethyl orthosilicate (TEOS; Sigma-Aldrich) was added. The mixture was then stirred at the same temperature overnight. The particles were subsequently collected by centrifugation and washed three times in ethanol. The particles were then dried in a desiccator and ground using a mortar and pestle.

\section{Synthesis of SNP04 and SNP05}

Absolute ethanol $(30 \mathrm{~mL})$ was mixed with $3 \mathrm{~mL}$ of $0.25 \mathrm{mg} / \mathrm{mL}$ potassium chloride solution. Ammonium hydroxide (28-30\%) was added at either (i) $1.5 \mathrm{~mL}$ for SNP04 or (ii) $3 \mathrm{~mL}$ for SNP05, and the mixture placed on a heated stirrer at $35^{\circ} \mathrm{C}$. In a separate tube, $3.5 \mathrm{~mL}$ TEOS was mixed with (i) $21 \mathrm{~mL}$ ethanol for SNP04 or (ii) $10.5 \mathrm{~mL}$ ethanol for SNP05 and vortexed (mix 2). Once the temperature had stabilized, either (i) $21 \mathrm{~mL}$ for SNP04 or (ii) $12 \mathrm{~mL}$ for SNP05, of mix 2 was added to the first flask. The final mixture was incubated at $35^{\circ} \mathrm{C}$ 
for either $4 \mathrm{~h}$ (SNP04) or overnight (SNP05). The particles were subsequently collected by centrifugation and washed three times in ethanol. The particles were then dried in a desiccator and ground using a mortar and pestle.

\section{Synthesis protocol of MSNPs}

Seven different mesoporous silica nanoparticles (MSNPs) were synthesized with varying external diameter and porosity. The first four had small pores (SP) and were designated SP1, SP2, SP3 and SP4. The latter three had much larger pores (LP) and were named LP1, LP2 and LP3. Santa Barbara Amorphous particles (SBA-15) were synthesized by Cristália Produtos Químicos Farmacêuticos Ltda, Brazil. These were included as a comparison since they have been used previously in adjuvant studies in the literature.

\section{Synthesis protocol of SP1}

Particles were made after the method of Zukal et al. (2007). In a typical synthesis process, $300 \mathrm{mg}$ of 1methyl-3-octylimidazolium chloride (OMIMCl), $100 \mathrm{mg}$ of cetyl trimethylammonium bromide (CTAB) and $400 \mathrm{mg}$ of sodium silicate $\left(\mathrm{Na}_{2} \mathrm{SiO}_{3}\right)$ were dissolved in $90 \mathrm{~mL}$ of $\mathrm{ddH}_{2} \mathrm{O}$ in a $250 \mathrm{~mL}$ round-bottom glass flask at room temperature. After the solution cleared by stirring for at least $1 \mathrm{~h}, 0.5 \mathrm{ml}$ of ethyl acetate was quickly added whilst stirring. After $1 \mathrm{~min}$, the stirring was stopped, and within $10 \mathrm{~min}$ at room temperature, a precipitate began to form. The mixture was allowed to stand at $35^{\circ} \mathrm{C}$ for a further $5 \mathrm{~h}$. The suspension was then heated to $95^{\circ} \mathrm{C}$, and the mixture stirred slowly for $48 \mathrm{~h}$. During the ageing process, organic vapour was allowed to escape. The resulting solid phase was recovered by

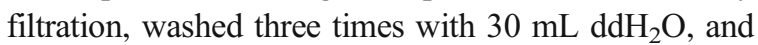
then washed a further three times with $30 \mathrm{~mL} \mathrm{MeOH}$. The template was removed as below.

\section{Template removal}

To remove the surfactant, the particles were resuspended in acidic methanol ( $40 \mathrm{~mL}$ methanol; $2 \mathrm{~mL} \mathrm{37 \%} \mathrm{hydro-}$ chloric acid). The system was then refluxed at $80{ }^{\circ} \mathrm{C}$ for $24 \mathrm{~h}$. After reflux, the suspension was allowed to cool down to room temperature, and particles collected and washed as in "THP-1 cell culture", with the exception that ethanol was used for washing in place of methanol.
The particles were dried in a desiccator under high vacuum for at least $24 \mathrm{~h}$ at room temperature. Subsequently, the particles were ground to a fine powder using a mortar and pestle.

\section{Synthesis protocol of SP2}

Particles were made after the method described in Huang et al. (2014). In a typical synthesis process, $200 \mathrm{mg}(\mathrm{CTAB})$ was dissolved in $96 \mathrm{~mL} \mathrm{ddH}_{2} \mathrm{O}$, and $700 \mu \mathrm{L}$ of $2 \mathrm{M}$ sodium hydroxide $(\mathrm{NaOH})$ solution was added, in a $250-\mathrm{mL}$ round-bottom glass flask. The mixture was then stirred and heated to $80{ }^{\circ} \mathrm{C}$. Once the temperature was attained, $1 \mathrm{~mL}$ tetraethyl orthosilicate (TEOS) was added, and the reaction kept at $80{ }^{\circ} \mathrm{C}$ for $2 \mathrm{~h}$. The mixture was then allowed to cool to room temperature and the particles collected by centrifugation for $3 \mathrm{~min}$ at 12,000 rpm for $3 \mathrm{~min}$. The particles were then resuspended in $30 \mathrm{~mL} \mathrm{MeOH}$ and centrifuged. This washing step was repeated three times.

\section{Synthesis protocol of SP3}

Particles were made after the method of He et al. (2009). In a typical process, $365 \mathrm{mg}$ CTAB was dissolved in $99.5 \mathrm{~mL}$ buffer solution (comprising $25 \mathrm{mM} \mathrm{KH}_{2} \mathrm{PO}_{4}$; $14.5 \mathrm{mM} \mathrm{NaOH} ; \mathrm{pH} \mathrm{7)}$ and $0.5 \mathrm{~mL}$ glycerol under vigorous stirring at $95{ }^{\circ} \mathrm{C}$. When the solution became homogeneous, $1.78 \mathrm{~mL}$ TEOS was added slowly into the system. The reaction was maintained at $95{ }^{\circ} \mathrm{C}$ for

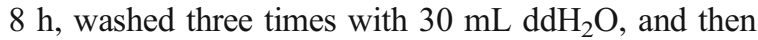
washed a further three times with $30 \mathrm{~mL} \mathrm{MeOH}$. The template was removed as described above.

\section{Synthesis protocol of SP4}

Particles were made after the method of $\mathrm{Du}$ and $\mathrm{He}$ 2010. In a typical synthesis process, $800 \mathrm{mg}$ CTAB

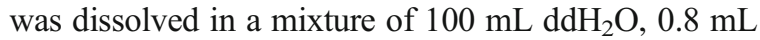
$\mathrm{NH}_{4} \mathrm{OH}, 20 \mathrm{~mL}$ ether and $20 \mathrm{~mL}$ ethanol, with constant stirring in a $250-\mathrm{mL}$ round-bottom glass flask at room temperature. After a clear solution was obtained, $2.5 \mathrm{~mL}$ TEOS was added to the solution. After vigorous stirring for $4 \mathrm{~h}$ at room temperature, a white precipitate was obtained. The particles were collected by centrifugation and resuspended in $30 \mathrm{~mL}$ methanol and centrifuged again. This washing step was repeated twice more. The template was removed as described above. 
Synthesis protocol of LP1

In a typical synthesis, $1 \mathrm{~g}$ CTAB was added to $15 \mathrm{~mL}$ $2 \mathrm{M}$ urea solution and stirred vigorously at room temperature. To the mixture, cyclohexane $(25.6 \mathrm{~mL})$ and butan-1-ol $(1.234 \mathrm{~mL})$ were added and the system heated at $40{ }^{\circ} \mathrm{C}$ for at least $1 \mathrm{~h}$ before proceeding. TEOS $(2.68 \mathrm{~mL})$ was then added dropwise and stirring continued for $30 \mathrm{~min}$ before increasing the heat to $70{ }^{\circ} \mathrm{C}$ for another $24 \mathrm{~h}$. The system was then cooled to room temperature, and $100 \mathrm{~mL}$ ethanol added. The particles were then collected by centrifugation at $12,000 \mathrm{rpm}$ for $5 \mathrm{~min}$. The particles were then resuspended in $30 \mathrm{~mL}$ acetone and centrifuged again. This wash step was repeated once, and then repeated twice using water, and then repeated twice using ethanol to wash. The template was removed as described above.

\section{Synthesis protocol of LP2}

In a typical synthesis, $500 \mathrm{mg}$ cetylpyridinium bromide (CPB) was dissolved in $15 \mathrm{~mL}$ urea $(20 \mathrm{mg} / \mathrm{mL})$ and stirred vigorously at room temperature. Cyclohexane $(15 \mathrm{~mL})$ was added while stirring, followed by $0.55 \mathrm{~mL}$ butan-1-ol. The solution was stirred for $3 \mathrm{~h}$. Subsequently, $1.34 \mathrm{~mL}$ of tetraethyl orthosilicate (TEOS) was added dropwise into the system and stirring continued for another $30 \mathrm{~min}$ at room temperature. The reaction mix was then maintained at $70{ }^{\circ} \mathrm{C}$ for a further $16 \mathrm{~h}$. After removal from the heat, $100 \mathrm{~mL}$ ethanol was added. The nanoparticles were then collected by centrifugation at 12,000 rpm for $5 \mathrm{~min}$. The particles were then washed with acetone and re-centrifuged, followed by resuspension in water and centrifugation. The template was removed as described above.

\section{Synthesis protocol of LP3}

The protocol was as for LP2 with the exception that butan-1-ol was replaced with $0.65 \mathrm{~mL}$ pentanol.

\section{Synthesis protocol of SNP01}

Absolute ethanol ( $48 \mathrm{~mL}$ ) was added to deionized water $(3 \mathrm{~mL})$ and ammonium hydroxide ( $3 \mathrm{~mL} ; 28 \%$ to $30 \%)$ and the mixture heated to $55^{\circ} \mathrm{C}$. TEOS $(3 \mathrm{~mL})$ was added to the system, and the mixture was stirred at $55^{\circ} \mathrm{C}$ for $16 \mathrm{~h}$. The particles were collected by centrifugation and washed three times with ethanol. The particles were dried in a desiccator and ground using a mortar and pestle.

FITC labelling of particles

FITC-APTES was prepared in an anaerobic chamber by the addition of $100 \mu \mathrm{l}$ of 3-aminopropyl triethoxysilane (APTES; Sigma) to $25 \mathrm{mg}$ fluorescein isothiocyanate (FITC; Sigma) in $5 \mathrm{~mL}$ dry ethanol. The mixture was covered to protect from light and stirred overnight at room temperature. The resulting FITC-APTES was stored at $4{ }^{\circ} \mathrm{C}$.

For labelling, silica nanoparticles were resuspended at $25 \mathrm{mg} / \mathrm{mL}$ in ethanol. The suspension was sonicated using a probe sonicator for $2 \mathrm{~min}$, and then $20 \mu \mathrm{l}$ of FITC-APTES was added to every millilitre of nanoparticle suspension and stirred overnight at room temperature. The labelled nanoparticles were collected by centrifugation, and then washed three times with ethanol. The particles were dried in a desiccator with care to avoid exposure to light.

\section{Zeta potential}

The surface charge of the particles was measured using a Zetasizer Nano ZS (Malvern, UK). To determine the electrokinetic potential, or $\zeta$ potential, the particles were suspended in distilled water ( $\mathrm{pH} 7)$ prior to measurement. The suspension was used to fill a DTS1070 disposable capillary cell. After $120 \mathrm{~s}$ equilibrium time, 30 runs were read before the calculation of zeta potential.

\section{Disc centrifuge}

The hydrodynamic particle size distributions were determined using a Disc Centrifuge (DC24000; CPs instrument). Prior to measurements, a sucrose gradient was built and PVC particle calibration standards were applied (266 nm; PVC000266, Analytic Ltd.).

Antigen loading of nanoparticles

The diphtheria toxoid was kindly provided by Fundação Butantan to Cristália Produtos Químicos Farmacêuticos Ltda. Silica nanoparticles were resuspended in PBS at a concentration of $5 \mathrm{mg} / \mathrm{mL}$. The MSNP stock suspension was sonicated using a VibraCell VC500 sonicator for $1 \mathrm{~min}(5 \mathrm{~s}$ on/ $5 \mathrm{~s}$ off). Inactivated diphtheria toxoid (DT) added to a final concentration of $2 \mathrm{mg} / \mathrm{mL}$, and 
mixed well. Loading was allowed to proceed for $24 \mathrm{~h}$ at $4{ }^{\circ} \mathrm{C}$.

\section{Statistical analysis}

All data is presented as the mean \pm standard deviation, and where appropriate, the student $t$ test was used to determine statistical significance $\left(* p<0.05,{ }^{*} p<0.01\right.$, $* * * p<0.005)$.

\section{Results}

To assess the uptake of the different silica nanoparticles, and to determine whether this was affected by size, porosity or loading, we tested the ability of the particles to be taken up into macrophage-like cells. In all phagocytosis assays performed, THP-1 cells were used and differentiated using $100 \mathrm{ng} / \mathrm{mL}$ PMA for $72 \mathrm{~h}$. The light scatter plot (Fig. 1; panel (i)) shows the changes in the populations of cells before and after treatment with PMA to differentiate the cells. The population of cells in the control and after treatment with PMA for $72 \mathrm{~h}$ shows homogeneous cell populations, whereas treatment for $48 \mathrm{~h}$ is an intermediate state with two populations of cells. To confirm the differentiation of the THP1 cells, CD-14 expression (a surface marker normally overexpressed in macrophages) was evaluated. An APC-labelled CD-14 antibody shows emission in the $660 \mathrm{~nm}$ (red) region and was used to assess the expression of the glycoprotein (Fig. 1; panel (ii)). The median fluorescence intensity increases from 3.95 (control) to 14.73 and 20.98 after incubation with PMA for 48 and $72 \mathrm{~h}$, respectively. Therefore, PMA can be seen to have successfully increased the expression of CD-14 and by implication resulted in the differentiation of the cells into macrophages. As further confirmation, the cells were examined microscopically (Fig. 1; panel (iii)). The morphology of the cells can be seen to change over the period of incubation with PMA and to give the appearance of macrophages after $72 \mathrm{~h}$.

Solid, spherical nanoparticles were synthesized in a range from $113.25 \pm 7.34$ to $847.25 \pm 27.54 \mathrm{~nm}$ in diameter (Table 1). The nanoparticles were imaged by SEM to confirm morphology and the diameter assessed using CPS disc centrifuge. Multiple batches were prepared for each to ensure that the methodology was robust and repeatable.
The solid spherical particles were then tested for their ability to be internalized by macrophages. However, when using fluorescence as a marker on the particles, it is important to be able to differentiate between cell surface-associated particles and those which have been genuinely internalized. To control for this factor, all experiments were performed at room temperature, and then replicated at low temperature (Johnstone et al. 2001; Gottstein et al. 2013). Active transport of the nanoparticles into cells ceases under low temperature conditions, and therefore, any fluorescence seen would be due to surface attachment and so was subtracted. It can be seen that uptake increases from SNP01 to SNP03, i.e. in the order $113.25 \mathrm{~nm}, 275.78 \mathrm{~nm}$ and $377.63 \mathrm{~nm}$ (Fig. 2a). Subsequently, there is no significant increase in the amount of $588.00 \mathrm{~nm}$ internalized into the macrophages. Once the size reaches $847.25 \mathrm{~nm}$, there is a significant decrease in the amount internalized compared to the peak uptake for $377.63 \mathrm{~nm}$ particles. This implies that there may be an optimal size for macrophage uptake of solid spherical silica nanoparticles peaking in the region of $377 \mathrm{~nm}$. Although the individual SBA-15 is not as large as SNP05, the particles are rod-shaped and often severely aggregated, and therefore may not be taken up as readily.

While it is useful to look at the different uptakes of solid particles due to their identical morphology, they are unable to carry cargo. We therefore investigated the uptake of a series of mesoporous silica particles (Table 2). These particles have been previously characterized in terms of their capacity to carry antigen (Huang et al. submitted as Part 1 of 2). The size of the pores and the zeta potential is also reported in Huang et al. submitted as Part 1 of 2 . It can clearly be seen that a similar pattern of uptake is seen with the MSNPs with respect to uptake and their external diameter. There is an increase in uptake from SP2 to LP2, i.e. $138 \mathrm{~nm}$, $202.66 \mathrm{~nm}$ and $217.20 \mathrm{~nm}$. There is a significant decrease in uptake between LP2 and LP3, LP1, SP3 and SP1, i.e. $217.20 \mathrm{~nm}$ and $217.75 \mathrm{~nm}, 462.33 \mathrm{~nm}, 496.96 \mathrm{~nm}$ and $1509.73 \mathrm{~nm}$. Here, the rod-shaped SBA-15 particles were taken up to a similar extent to LP1, i.e. $612.75 \mathrm{~nm}$ and $462.33 \mathrm{~nm}$, respectively. SP3 is only slightly larger than LP1, i.e. $462.33 \mathrm{~nm}$ compared to $496.93 \mathrm{~nm}$, yet there is a very significant decrease in uptake. It is not clear why SP3 has a far lower uptake than SBA-15, although the synthesis method is slightly unusual in that it uses glycerol as the co-surfactant and co-solvent [23]. The zeta potential of the particles is all very similar and so not likely to cause 


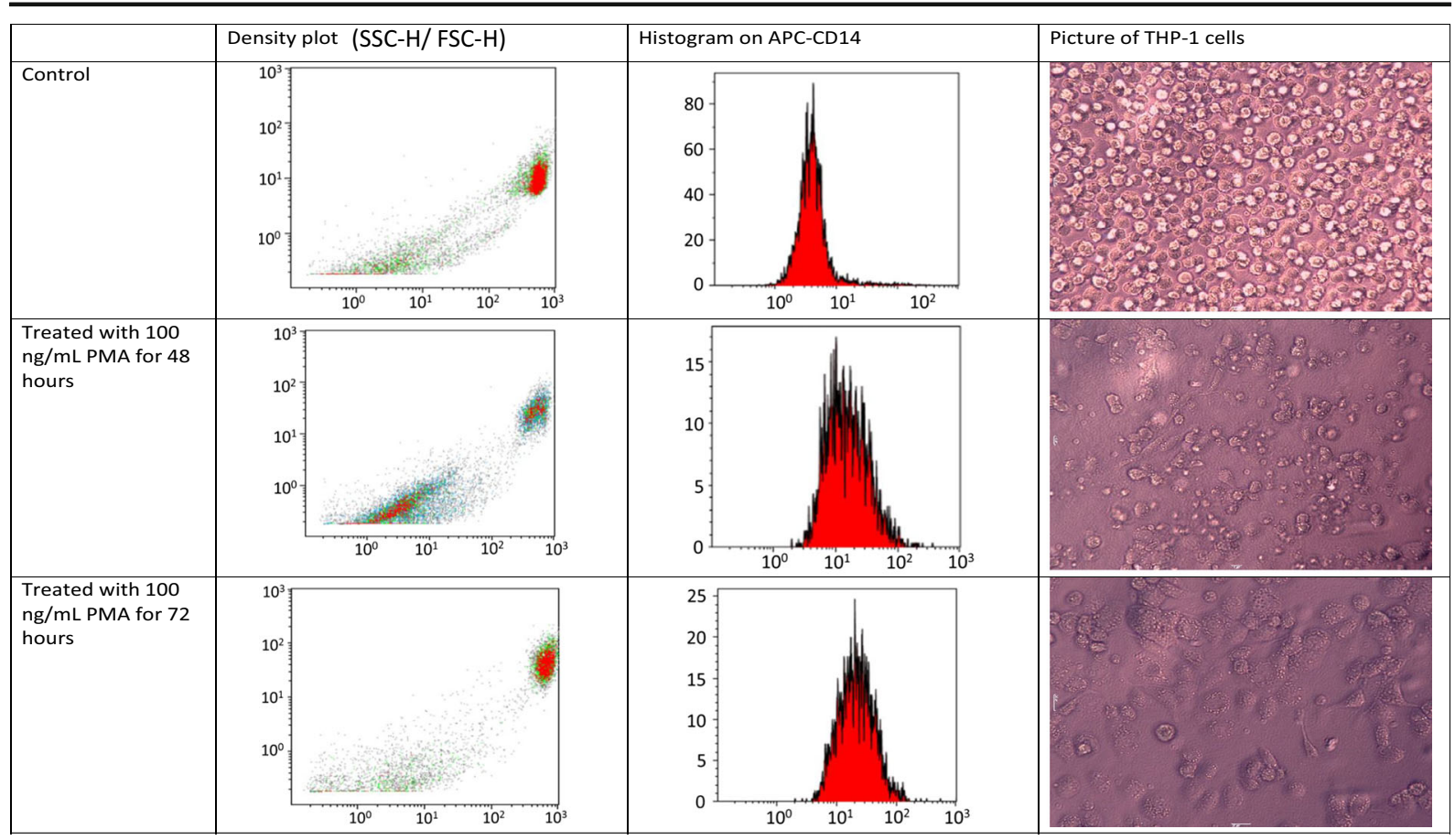

Fig. 1 Differentiation of THP-1 cells after incubation with PMA a Control; no PMA, b after treatment with $100 \mathrm{ng} / \mathrm{mL}$ PMA for $48 \mathrm{~h}$, c after treatment with $100 \mathrm{ng} / \mathrm{mL}$ PMA for $72 \mathrm{~h}$. Panel (i) shows

significant differences [3]. SP1 has a very large external diameter $(1509.73 \mathrm{~nm})$, and this is most likely the reason why this particle has a very low uptake.

The macrophage uptake experiments shown in Fig. 2b were for MSNPs without cargo. We subsequently tested whether the addition of antigen to the MSNPs would affect the uptake (Fig. 3). Due to their very poor

Table 1 The diameter of the solid spherical nanoparticles was assessed using CPS disc centrifugation. Zeta potential was determined using a Zetasizer Nano ZS (Malvern UK). Number of replicates indicates number of different batches of particles made and assessed. SBA-15 was assessed by SEM (due to rod-like shape). Number of replicates relates to the number of particles measured in the sample

\begin{tabular}{|c|c|c|c|c|}
\hline Name & Diameter (nm) & Potential (mV) & Particle name & Size \\
\hline SNP01 & $113.25 \pm 7.34(n=8)$ & $-19.93 \pm 3.36$ & SP1 & $1509.73 \pm 269.93$ \\
\hline SNP02 & $275.78 \pm 17.75(n=9)$ & $-27.27 \pm 1.00$ & SP2 & $138.51 \pm 26.29$ \\
\hline SNP03 & $377.63 \pm 11.36(n=8)$ & $-45.17 \pm 1.33$ & SP3 & $469.93 \pm 13.24$ \\
\hline SNP04 & $588.00 \pm 25.61(n=7)$ & $-45.20 \pm 0.44$ & SP4 & $202.66 \pm 19.65$ \\
\hline \multirow[t]{2}{*}{ SNP05 } & $847.25 \pm 27.54(n=8)$ & $-50.70 \pm 0.62$ & LP1 & $462.33 \pm 25.03$ \\
\hline & Length (nm) & & LP2 & $217.20 \pm 22.66$ \\
\hline SBA15 & $612.75 \pm 82.22(n=13)$ & $-19.70 \pm 0.30$ & LP3 & $217.75 \pm 5.44$ \\
\hline
\end{tabular}

light scatter plot of cells. Panel (ii) FL3 (red channel to detect APC-CD-14) indicates the expression of CD14 on THP-1 cells. Panel (iii) Microscope images show the morphology of the cells

uptake without cargo, SP3 and SP1 were omitted from this test (Huang et al. submitted as Part 1 of 2). The largest particle in this test, LP1 $(462.33 \mathrm{~nm})$ showed the lowest uptake (Fig. 3a), similar to results seen in Fig. 2 b. The particles SP4 and LP2 showed the greatest changes in uptake after loading with diphtheria toxoid (Fig. 3b). SP4 uptake was significantly reduced $(p<0.005)$ from $56.8 \pm 0.5$ to $38.2 \pm 0.4 \%$, and LP2 uptake was significantly reduced $(p<0.005)$ from $64.8 \pm 1.9$ to $42.9 \pm$ $0.3 \%$. It is not clear why these particles would behave so differently since there is no observable difference in

Table 2 The diameter of the mesoporous silica nanoparticles was assessed using CPS disc centrifuge. Data shows mean \pm standard deviation 
Fig. 2 Unloaded FITC-labelled MSNPs were assessed by FACS for their ability to be internalized by macrophages. a Solid spherical nanoparticles [SNP]. b Mesoporous silica nanoparticle with small pores $[\mathrm{SP}]$ and large pores [LP]. SBA-15 was used in each data set for comparison. Data is presented as mean \pm standard Deviation of triplicate samples and significance was tested using a one tailed t-test $(* p<0.05$;

$* * p<0.01 ; * * * p<0.005)$ a
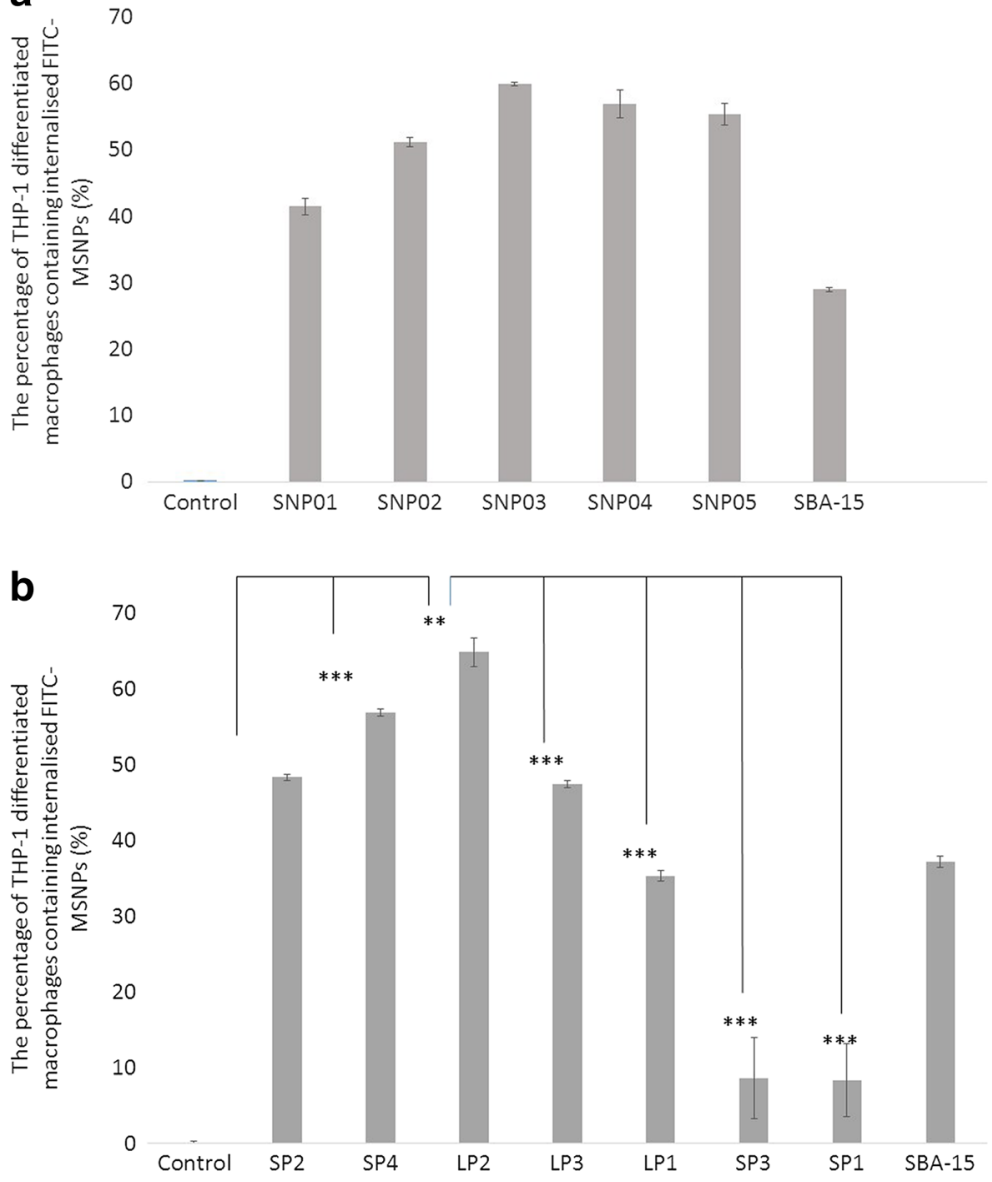

the particle surface charge, surface area or morphology that would explain why these two particles in particular had reduced uptake after loading.

We therefore looked at the hydrodynamic diameter of two of the MSNPs before and after loading see (Huang et al. An assessment of mesoporous silica nanoparticle architectures as antigen carriers). LP2 showed a very significant decrease in uptake into macrophages after loading. The size before loading was determined to be $217.20 \pm$ $22.66 \mathrm{~nm}$ (Fig. 3a). After incubation with diphtheria toxoid at a ratio of 1:20 for $24 \mathrm{~h}$ at $4{ }^{\circ} \mathrm{C}$, the size was $330.91 \pm$ $4.86 \mathrm{~nm}$, an increase of just over $50 \%$. In terms of size the increase in size would place it nearer to LP1 (462.33 \pm $25.03 \mathrm{~nm}$ ). Unloaded LP1 showed considerably reduced uptake compared to LP2, and so, the size increase could explain the reduction in uptake (Fig. 3b). In contrast, LP3 which was seen to have a modest increase in macrophage uptake after loading only increased in hydrodynamic diameter from $217.75 \pm 5.44 \mathrm{~nm}$ before loading to $270.61 \pm$ $1.99 \mathrm{~nm}$ after loading.
Once the ability of the macrophages to take up the various different particles had been determined, those which were taken up most readily were further examined for their effect on cell viability (Fig. 4). Both naked nanoparticles and those loaded with diphtheria toxoid were assessed. There was no difference seen between loaded and unloaded particles except for LP1 $(p<0.05)$. The LP1 particles showed the best biocompatibility as measured by survival of the macrophages $24 \mathrm{~h}$ after incubation with the particles, $88.1 \pm 3.0 \%$ and $87.0 \pm$ $4.6 \%$ for unloaded and loaded LP1, respectively. None of the particles, however, caused significant cell death with the lowest, DT-loaded SP4, showing a cell viability of $71.9 \%$ of the control.

Given the nanoparticle uptake by the cells (Figs. 2 and 3) and the relative viability of the cells (Fig. 4) after incubation with the particles, the performance of LP2 could be deemed the best, although with the exception of SP3 and SP1 which were poorly taken up by macrophages, all particles performed well. Interestingly, we 
Fig. 3 a Antigen loaded FITClabelled MSNPs were assessed by FACS for their ability to be internalized by macrophages. b Comparison of loaded (light grey) and unloaded (dark grey) particles. Data is presented as mean \pm standard deviation of triplicate samples and significance was tested using a one-tailed $t$ test $(* p<0.05, * * p<0.01$; $* * * p<0.005)$ a
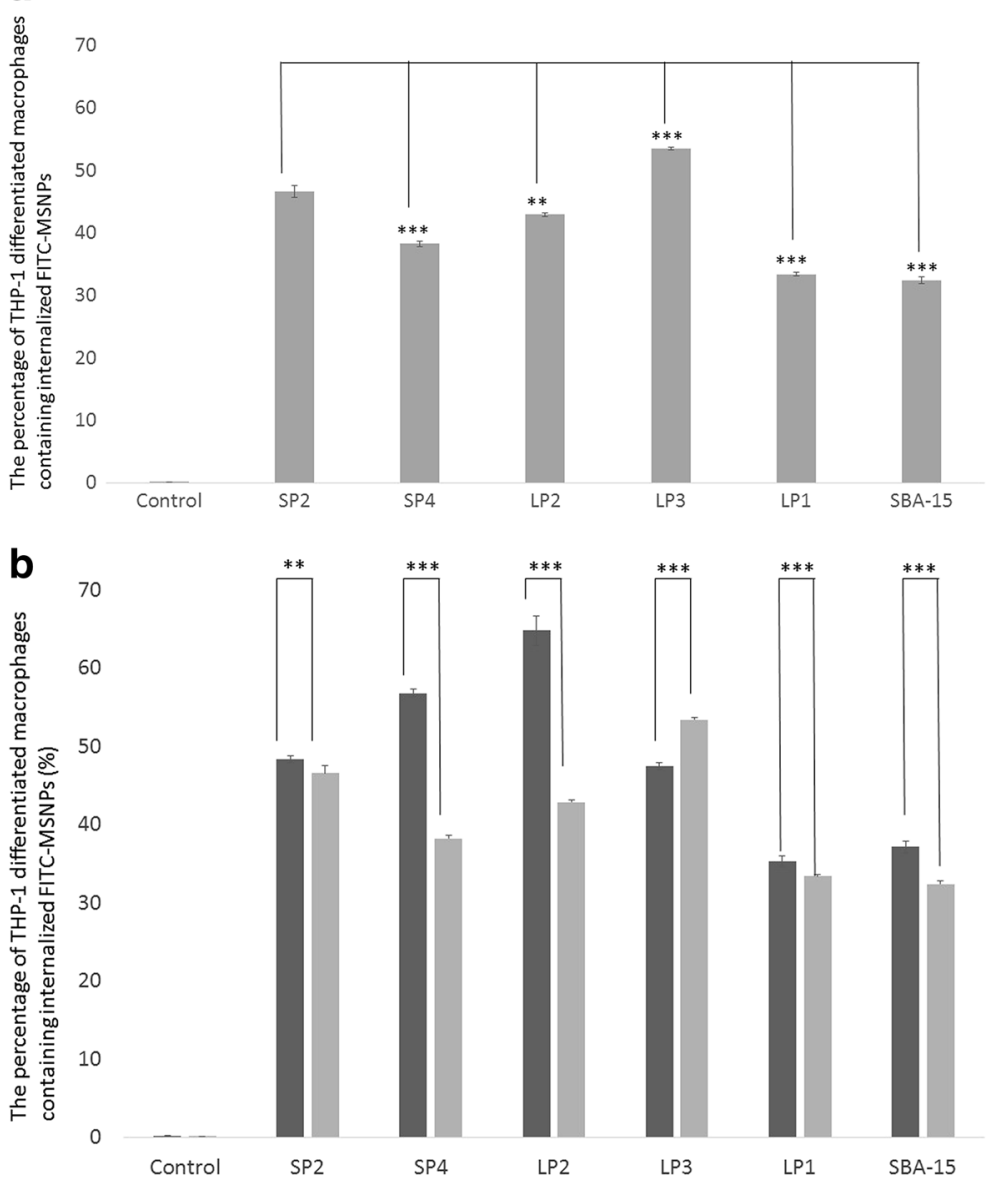

have previously shown that SP3 and SP1 also showed the lowest loading efficiency for diphtheria toxoid (Huang et al. submitted as Part 1 of 2).

\section{Discussion}

Macrophages are cells which form a part of the innate immune system and as such are able to engulf a wide variety of targets, including dead cells, dust, pollen and invading pathogens. Bacterial pathogens can differ greatly in their sizes, shapes and surface features, which can all have an effect on virulence (Cabeen and JacobsWagner 2005). This can give indications to the way in which macrophages would interact with man-made materials such as the MSNPs designed to stimulate the immune system.

In order to perform their role in the immune system, macrophages engulf particles by the process of phagocytosis (Burke and Lewis 2002). Phagocytosis involves both structural rearrangements of the cytoskeleton and membrane, and also a complex network of signalling events. The process of phagocytosis is affected by the physical parameters of the particles being engulfed. These can be split into geometric aspects such as the size (Pratten and Lloyd 1986; Tabata and Ikada 1988a, 1988b; Koval et al. 1998), shape or aspect ratio of the particles (Lengerova et al. 1957; Champion and Mitragotri 2006; Gratton et al. 2008; Sharma et al. 2010; Lu et al. 2010; Champion and Mitragotri 2009), surface properties (Tabata and Ikada 1988a, 1988b; Faraasen et al. 2003; Roser et al. 1998; Gilberti et al. 2008; Ahsan et al. 2002) and mechanical aspects (Beningo and Wang 2002).

To study the uptake of the particles by macrophages, we used the immortalized cell line THP-1 and used PMA for differentiation of the cells. One problem associated with assessing uptake is whether it can be 
Fig. 4 Relative viability of THP1 derived macrophages $24 \mathrm{~h}$ after treatment with $10 \mu \mathrm{g} / \mathrm{mL}$ unloaded FITC-MSNPs (black bars), or diphtheria toxoid loaded MSNPs (grey bars). Control indicates cells which have not been treated with any MSNPs. Data shows mean \pm standard deviation $(n=3)$. DT diphtheria toxoid. $(* p<0.05 ; * * p<0.01$ $* * * p<0.005)$

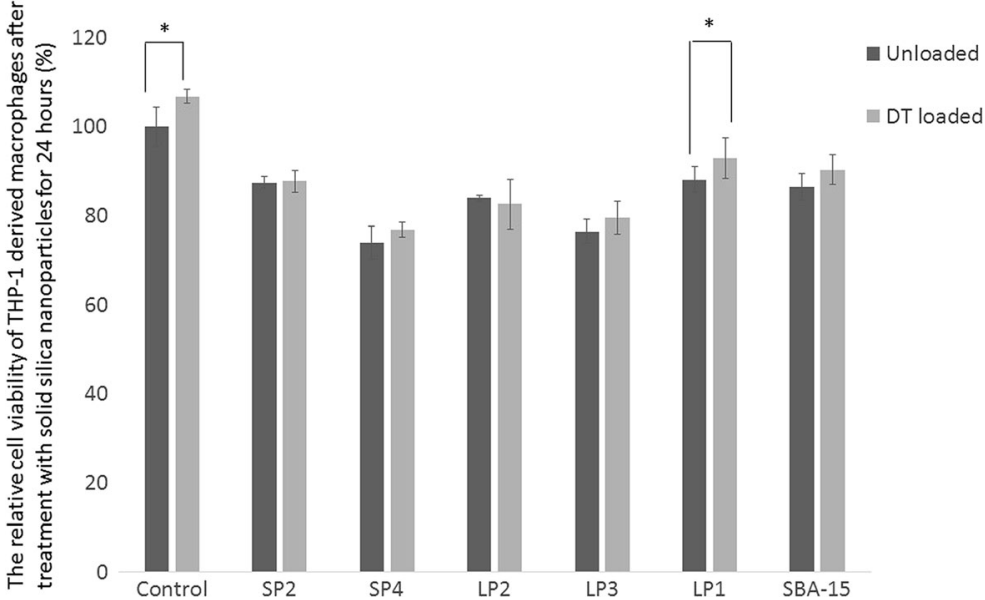

determined whether particles are attached to the surface of the cells, or have been truly internalized. Since the particles were labelled with FITC, they were to be observed via fluorescence. We therefore originally tried the methods which used the fact that trypan blue can quench green fluorescence from FITC (Avelar-Freitas et al. 2014). However, we found that the fluorescence was quenched from both external and internalized particles alike, so could not be used to differentiate uptake. We therefore explored the use of sodium azide, an inhibitor of phagocytosis, as a way to differentiate between particles which were phagocytosed compared to those which were merely surface bound. However, sodium azide has been shown to take up to $3 \mathrm{~h}$ of contact with cell culture before they have an effect on phagocytosis (Cifarelli et al. 1979) and can also inhibit oxidative phosphorylation. Since we were concerned that sodium azide could affect cell viability, this method was also not chosen. Consequently, we used low temperature to inhibit phagocytosis and subtracted any fluorescence which was detected after such treatment since this would be a result of surface-bound particles.

The highly cited silica particle SBA- 15 was used as a comparison molecule in all our experiments. This is a rod-shaped particle with an aspect ratio of $3: 1$. Our results showed uptake in the region of $30 \%$ (Fig. 2a). The low uptake is not unexpected since aspect ratio is known to affect uptake, with very high aspect ratios completely inhibiting phagocytosis (Gratton et al. 2008).

Size has often been considered the most important factor for uptake, and the optimal size for macrophage internalization has been cited as between 1 and $3 \mu \mathrm{m}$ (Pratten and Lloyd 1986; Koval et al. 1998; Tabata and
Ikada 1988a, 1988b; Champion et al. 2008). This was thought to correspond to the size of a number of large bacteria (Kubitschek 1969). However, our largest particle (SP1; $1509.73 \pm 269.93 \mathrm{~nm})$ showed the lowest uptake, and the optimal uptake was for much smaller particles. Of course, as has been the case with regard to aspect ratio, the shape of the particles is also important. In 2006, Champion and Mitragotri first demonstrated that the local shape at the point of contact with the membrane governs whether phagocytosis will be initiated, whilst the size will determine whether the process is completed. In addition to size and shape, the mesoporosity of silica nanoparticles has also been indicated in their biological interactions (Asefa and Tao 2012). Compared to solid silica nanoparticles, the mesoporosity of the MSNPs results in lower rigidity which buffers the interaction with biological entities. This also results in lowered interfacial energy between the nanomaterials and the biological surfaces. In our study, the greatest uptake for solid particles was for the SNP03 $(377 \mathrm{~nm})$ particles, whereas for the mesoporous particles, LP2 $(217 \mathrm{~nm})$ had the greatest uptake. However, the uptake for the mesoporous LP2 was slightly higher than for the solid spherical nanoparticle SNP03. The size of the pores on the MSNPs did not seem to affect the uptake, which was related only to external diameter of the particles (Fig. 1).

Surface charge has also been shown to be an important parameter in the degree of uptake of particles. Thiele et al. (2001) found that positively charged particles showed much greater uptake. For non-metallic nanoparticles, there was also a correlation between positive charge and the ability to elicit an immune response. However, negatively charged non-metallic 
nanoparticles were associated with antigen-specific tolerance (Fromen et al. 2016). Despite these studies, there still needs to be further investigation into whether a generalized statement with regard to the charge of the nanoparticle and its influence on the immune response. Silica nanoparticles have an inherent negative charge due to silanol groups on the surface. The solid silica nanoparticles synthesized in this study show increasing negative $\zeta$ potential with increasing size (Table 1). It is therefore difficult to separate charge and size in determining which factor contributes to the degree of uptake. The behaviour of the particles with regard to uptake by the macrophages altered after the MSNPs were loaded with DT. The DT has an isoelectric point of 4.1 (Pappenheimer 1937) and therefore under low pH conditions, the DT would be positively charged. The silica is negatively charged and so the DT would be electrostatically attracted. This means that not only would loading with DT potentially change the hydrodynamic size, but also the apparent charge of the loaded particle.

In addition to the size, shape and charge of the particles, the material may also influence the interaction with the macrophages. The material from which a nanoparticle is made has a direct influence on the functions of the antigen-presenting cells (Marques et al. 2017). Gold nanoparticles are one of the most studied in vaccinology (see Marques et al. 2017 for summary), but other metals such as iron oxide and nickel have also been investigated. Polymers have also been tested and for example, poly (lactic-co-glycolic acid) (PLGA) delivery systems have shown adjuvant activity (Nicolete et al. 2011), with both humoral and cellular responses (O'Hagan and Singh 2003; Men et al. 1999; Carcaboso et al. 2004). Other materials that have been explored include emulsifying wax (Cui and Mumper 2002), lecithin-glyceryl monostearate (Sloat et al. 2010), albumin, gelatin (Zwiorek et al. 2008), collage, chitosan and alginate (Sloat et al. 2010). We have chosen to investigate silica since it has the benefit of being easily manipulated to form mesoporous particles which have a very high surface area. MSNPs have been shown to have intrinsic adjuvant activity and to potentiate antigen-specific T cell immune responses (Kupferschmidt et al. 2014; Mahony et al. 2013). Furthermore, silica is widely reported to be biocompatible, and the nanoparticles degrade (Coppi et al. 2004) to the relatively harmless silicic acid (Diaconu et al. 2010).

\section{Conclusions}

More effective vaccines could benefit from improved, nanoparticulate delivery systems. Silica is a biocompatible material which has the potential to both carry antigen and act as an adjuvant. We investigated a range of sizes of silica nanoparticles to determine the effect on uptake by THP-1 macrophage-like cells. It was seen with both solid and mesoporous silica nanoparticles that smaller particles were less effectively taken up by macrophages. Optimal sizes appeared to be in the 200$400 \mathrm{~nm}$ range. We have previously demonstrated that antigen is stable on silica particles for at least 3 months (Huang et al. submitted as Part 1 of 2). MSNPs therefore present a viable alternative to current vaccine compositions.

Funding information This work was supported financially by a grant from Cristalia Produtos Quimicos Farmaceuticos LTDA, Brazil.

\section{Compliance with ethical standards}

Conflict of interest $\mathrm{XH}$ and HET received a research grant from Cristalia Produtos Quimicos Farmaceuticos LTDA, Brazil. DPC is an employee of Cristalia Produtos Quimicos Farmaceuticos LTDA, Brazil.

Open Access This article is licensed under a Creative Commons Attribution 4.0 International License, which permits use, sharing, adaptation, distribution and reproduction in any medium or format, as long as you give appropriate credit to the original author(s) and the source, provide a link to the Creative Commons licence, and indicate if changes were made. The images or other third party material in this article are included in the article's Creative Commons licence, unless indicated otherwise in a credit line to the material. If material is not included in the article's Creative Commons licence and your intended use is not permitted by statutory regulation or exceeds the permitted use, you will need to obtain permission directly from the copyright holder. To view a copy of this licence, visit http://creativecommons.org/licenses/by/4.0/.

\section{References}

Ahsan F, Rivas IP, Torres Suarez A (2002) Targeting to macrophages: role of physicochemical properties of particulate carriers - liposomes and microspheres - on the phagocytosis by macrophages. J Control Release 79:29-40

Alshanqiti FM, Al-Masaudi SB, Al-Hejin AM, Redwan EM (2017) Adjuvants for Clostridium tetani and Clostridium diphtheriae vaccines updating. Hum Antibodies 25:23-29 
Asefa T, Tao Z (2012) Biocompatibility of mesoporous silica nanoparticles. Chem Res Toxicol 25:2265-2284

Avelar-Freitas B, Almeida V, Pinto M, Mourão F, Massensini A, Martins-Filho O, Rocha-Vieira E, Brito-Melo G (2014) Trypan blue exclusion assay by flow cytometry. Braz J Med Biol Res 47:307-3015

Beningo KA, Wang Y-L (2002) Fc-receptor-mediated phagocytosis is regulated by mechanical properties of the target. J Cell Sci 115:849-856

Burke B, Lewis CE (eds) (2002) The macrophage. Oxford University Press, New York

Cabeen MT, Jacobs-Wagner C (2005) Bacterial cell shape. Nat Rev Microbiol 3:601-610

Carcaboso A, Hernandez R, Igartua M, Rosas J, Patarroyo M, Pedraz J (2004) Potent, long lasting systemic antibody levels and mixed Th1/Th2 immune response after nasal immunization with malaria antigen loaded PLGA microparticles. Vaccine 2:1423-1432

Champion JA, Mitragotri S (2006) Role of target geometry in phagocytosis. PNAS 103:4930-4934

Champion JA, Mitragotri S (2009) Shape induced inhibition of phagocytosis of polymer particles. Pharm Res 26:244-249

Champion J, Walker A, Mitragotri S (2008) Role of particle size in phagocytosis of polymeric microspheres. Pharm Res 25: $1815-1821$

Chattopadhyay S, Chen J-Y, Chen H-W, Hu C-M (2017) Nanoparticle vaccines adopting virus-like features for enhanced immune potentiation. Nanotheranostics 1:244-260

Cheng K, El-Boubbou K, Landry CC (2012) Binding of HIV-1 gp120 glycoprotein to silica nanoparticles modified with CD4 glycoprotein and CD4 peptide fragments. ACS Appl Mater Interfaces 4:235-243

Cifarelli A, Pepe G, Paradisi F, Piccolo D (1979) The influence of some metabolic inhibitors on phagocytic activity of mouse macrophages in vitro. Res Exp Med (Berl) 174:197-204

Coppi G, Iannuccelli V, Sala N, Bondi M (2004) Alginate microparticles for Polymyxin B Peyer's patches uptake: microparticles for antibiotic oral administration. J Microencapsul 21: 829-839

Cui Z, Mumper RJ (2002) Topical immunization using nanoengineered genetic vaccines. J Control Release 81: 173-184

Diaconu M, Tache A, Eremia M, Gatea F, Litescu S et al (2010) Structural characterization of chitosan coated silicon nanoparticles - a FTIR approach. UPB Sci Bull:72

Du X, He J (2010) Fine-tuning of silica nanosphere structure by simple regulation of the volume ratio of cosolvents. Langmuir 26:10057-10062

Faraasen S, Vörös J, Walter E (2003) Ligand-specific targeting of microspheres to phagocytes by surface modification with poly(L-lysine)-grafted poly (ethylene glycol) conjugate. Pharm Res 20:237-246

Foged C, Brodin B, Frokjaer S, Sundblad A (2005) Particle size and surface charge affect particle uptake by human dendritic cells in an in vitro model. Int J Pharm 298:315-322

Fromen CA, Rahhal TB, Robbins GR, Kai MP, Shen TW, Luft JC, DeSimone J (2016) Nanoparticle surface charge impacts distribution, uptake and lymph node trafficking by pulmonary antigen-presenting cells. Nanomedicine 12:677-687
Gilberti RM, Joshi GN, Knecht DA (2008) The phagocytosis of crystalline silica particles by macrophages. Am J Respir Cell Mol Biol 39:619-627

Glenny AT, Hopkins BE (1923) Diphtheria toxoid as an immunising agent. Br J Exp Pathol 4:283-287

Gottstein C, Wu G, Wong B, Zasadzinski J (2013) Precise quantification of nanoparticle internalization. ACS Nano 7:49334945

Gratton SE, Ropp PA, Pohlhaus PD, Luft JC, Madden VJ, Napier ME, DeSimone JM (2008) The effect of particle design on cellular internalization pathways. PNAS. 105:11613-11618

Guo HC, Feng XM, Sun SQ, Wei YQ, Sun DH, Liu XT, Liu ZX, Luo JX, Yin H (2012) Immunization of mice by hollow mesoporous silica nanoparticles as carriers of porcine circovirus type 2 ORF2 protein. Virol J 9:108

He Q, Cui X, Cui F et al (2009) Size-controlled synthesis of monodispersed mesoporous silica nano-spheres under a neutral condition. Microporous Mesoporous Mater 117:609-616

Huang X, Young NP, Townley HE (2014) Characterization and comparison of mesoporous silica particles for optimized drug delivery. Nanomater Nanotechnol 4:2

Huang et al. submitted to J. Nano Res as paper 1 of this pair

Johnstone S, Masin D, Mayer L, Bally M (2001) Surfaceassociated serum proteins inhibit the uptake of phosphatidylserine and poly (ethylene glycol) liposomes by mouse macrophages. Biochim Biophys Acta Biomembr 1513:25-37

Koval M, Preiter K, Steinberg TH (1998) Size of IgG-opsonized particles determines macrophage response during internalization. Exp Cell Res 242:265-273

Kubitschek HE (1969) Growth during the bacterial cell cycle: analysis of cell size distribution. Biophys J 9:792-809

Kupferschmidt N, Qazi KR, Kemi C, Vallhov H, Garcia-Bennett AE, Gabrielsson S, Scheynius A (2014) Mesoporous silica particles potentiate antigen-specific T-cell responses. Nanomedicine 9:1835-1846

Lengerova A, Lenger VJ, Volfova M (1957) The influence of the shape of dust particles on the rate of phagocytosis in vitro. $\mathrm{Br}$ $\mathrm{J}$ Ind Med 14:43-46

Lu Z, Qiao Y, Li CM (2010) Effect of particle shape on phagocytosis of CdTe quantum dot-cystine composites. Med Chem Commun 1:84-86

Mahony D, Cavallaro AS, Stahr F, Mahony TJ, Qiao SZ, Mitter N (2013) Mesoporous silica nanoparticles act as a self-adjuvant for ovalbumin model antigen in mice. Small 9:3138-3146

Marques N, Lázaro M, Kipnis A, Junqueira-Kipnis AP (2017) Role of metallic nanoparticles in vaccinology: implications for infectious disease vaccine development. Front Immunol 8:239

McCusker C, Yilmaz T, Rotello V (2004) Toxicity of gold nanoparticles functionalized with cationic and anionic side chains. Bioconjug Chem 15:4897-4900

Men Y, Audran R, Thomasin C, Eberl G, Demotz S, Merkle H, Gander B, Corradin G (1999) MHC class I- and class IIrestricted processing and presentation of microencapsulated antigens. Vaccine 17:1047-1056

Mercuri LP, Carvalho LV, Lima FA, Quayle C, Fantini MC, Tanaka GS, Cabrera WH, Furtado MF, Tambourgi DV, Matos Jdo R, Jaroniec M, Sant'Anna OA (2006) Ordered mesoporous silica SBA-15: a new effective adjuvant to induce antibody response. Small 2:254-256 
Nicolete R, dos Santos D, Faccioli L (2011) The uptake of PLGA micro or nanoparticles by macrophages provokes distinct in vitro inflammatory response. Int Immunopharmacol 11: 1557-1563

Nuhn L, Vanparijs N, De Beuckelaer A, Lybaert L, Verstraete G, Deswarte $\mathrm{K}$ et al (2016) pH-degradable imidazoquinolineligated nanogels for lymph node-focused immune activation. Proc Natl Acad Sci U S A 113:8098-8103

O'Hagan D, Singh M (2003) Microparticles as vaccine adjuvants and delivery systems. Expert Rev Vaccines 2:269-283

Pappenheimer A (1937) Diptheria toxin I. Isolation and characterization of a toxic protein from Corynebacterium diphtherue filtrates. J Biol Chem 120:543-553

Pobre K, Tashani M, Ridda I, Rashid H, Wong M, Booy R (2014) Carrier priming or suppression: understanding carrier priming enhancement of anti-polysaccharide antibody response to conjugate vaccines. Vaccine 32:1423-1430

Pratten MK, Lloyd JB (1986) Pinocytosis and phagocytosis: the effect of size of a particulate substrate on its mode of capture by rat peritoneal macrophages cultured in vitro. Biochim Biophys Acta 881:307-313

Ramon G (1924) Sur la toxoide et sur l'anatoxine diphtérique. Ann Inst Pasteur 38:1-10

Roser M, Fischer D, Kissel T (1998) Surface-modified biodegradable albumin nano- and microspheres. II: Effect of surface charges on in vitro phagocytosis and biodistribution in rats. Eur J Pharm Biopharm 46:255-263

Schwende H, Fitzke E, Ambs P, Dieter P (1996) Differences in the state of differentiation of THP-1 cells induced by phorbol ester and 1,25-dihydroxyvitamin D3. J Leukoc Biol 59:555561

Sharma G, Valenta DT, Smith JW (2010) Polymer particle shape independently influences binding and internalization by macrophages. J Control Release 147:408-412
Sloat BR, Sandoval MA, Hau AM, He Y, Cui Z (2010) Strong antibody responses induced by protein antigens conjugated onto the surface of lecithin-based nanoparticles. J Control Release 141:93-100

Tabata Y, Ikada Y (1988a) Effect of the size and surface charge of polymer microspheres on their phagocytosis by macrophage. Biomaterials 9:356-362

Tabata Y, Ikada Y (1988b) Macrophage phagocytosis of biodegradable microspheres composed of 1-lactic acid/glycolic acid homo- and copolymers. J Biomed Mater Res 22:837858

Thiele L, Rothen-Rutishauser B, Jilek S, Wunderli-Allenspach H, Merkle HP, Walter E (2001) Evaluation of particle uptake in human blood monocyte-derived cells in vitro. Does phagocytosis activity of dendritic cells measure up with macrophages? J Control Release 76:59-71

Tsuchiya S, Yamabe M, Yamaguchi Y, Kobayashi Y, Konno T, Tada K (1980) Establishment and characterization of a human acute monocytic leukemia cell line (THP-1). Int J Cancer 26:171-176

Zhao L, Seth A, Wibowo N, Zhao CX, Mitter N, Yu C, Middelberg AP (2014) Nanoparticle vaccines. Vaccine 32: 327-337

Zukal A, Thommes M, Cejka J (2007) Preparation of MCM-41 silica using the cationic surfactant blend. Microporous Mesoporous Mater 104:52-58

Zwiorek K, Bourquin C, Battiany J, Winter G, Endres S, Hartmann G, Coester C (2008) Delivery by cationic gelatin nanoparticles strongly increases the immunostimulatory effects of CpG oligonucleotides. Pharm Res 25:551-562

Publisher's note Springer Nature remains neutral with regard to jurisdictional claims in published maps and institutional affiliations. 